\title{
Structural Evolution and Motion Characteristics of a Hard Roof During Thickening Coal Seam Mining
}

\author{
Xiangyang Zhang, Xiangyang Zhao *and Lei Luo \\ School of Mining Engineering, Anhui University of Science and Technology, Huainan, China
}

OPEN ACCESS

Edited by:

Kun Du,

Central South University, China

Reviewed by:

Jian Cui,

Tianjin University, China Jinwang Zhang,

China University of Mining and

Technology, China

*Correspondence:

Xiangyang Zhao

673908201@qq.com

Specialty section:

This article was submitted to

Geohazards and Georisks,

a section of the journal

Frontiers in Earth Science

Received: 14 October 2021 Accepted: 31 December 2021

Published: 10 February 2022

Citation:

Zhang X, Zhao X and Luo L (2022)

Structural Evolution and Motion Characteristics of a Hard Roof During

Thickening Coal Seam Mining.

Front. Earth Sci. 9:794783.

doi: 10.3389/feart.2021.794783
This study combined theoretical analysis, physical simulation, and numerical simulation to discuss the influences of the structural evolution and motion characteristics of a hard roof during thickening coal seam mining on working face pressure. Results showed that during the mining of the thickening coal seam with a hard roof, the settlement curve of low-level strata was a stepwise wave slope, and the settlement curve of high-level strata shifted from a "V-shaped" distribution pattern to a parabola under the full mining of the coal seam. When the mining thickness was relatively small, the mining space expanded with the increase in mining thickness due to the "masonry beam" structure formed by the low-level, sub-critical overlying strata. The low-level critical strata formed a "composite cantilever beam" structure with a hard immediate roof after advancing into the caving zone. After complete recovery, the overlying strata were in a steady-movement state, and the plastic failure zone of the overlying strata of the thickening coal seam presented obvious distribution characteristics of longitudinal and transverse partitions. This study provides theoretical reference for coal seam mining under similar geological conditions.

Keywords: hard roof, thickening coal seam, overlying strata structure, motion characteristics, physical simulation, numerical simulation

\section{INTRODUCTION}

Decades-long production practices have shown that the caving height of overlying strata in a goaf increases, and the sphere of influence of the overlying strata on the working face pressure expands as the disposal mining thickness increases in fully mechanized caving mining of thick coal seams. Meanwhile, a main roof with a hinged balance structure at low-level positions of the fully mechanized mining face might change into an immediate roof. Studying the structural morphology and motion type of overlying strata in the stope is the basis of analyzing the behavior law of working face pressure.

In this regard, a lot of studies have been carried worldwide. Generally, deformation, fracture propagation, and energy release are highly associated with mining-induced stress evolution (Gao et al., 2021). After mining, the state of stress equilibrium is disturbed by an opening formed due to underground extraction of part of the coal seam (Wang et al., 2018a), resulting in the change of overburden structure above the coal seam. Zhang (Zhang and Wang, 1998) pointed out that there is a stable "masonry beam" above the stope and a "semi-arch" structure below the "masonry beam." The combination of the two forms the basic form of overburden structure of a fully mechanized caving face. The cantilever beam is formed by the rupture of low-level critical strata in a fully mechanized caving face, whereas the masonry beam is formed in high-level critical strata (Huang et al., 2020; Kong et al., 2020; Li et al., 2018). The higher the mining height, the closer the subcritical stratum is to the coal seam, and the easier it is to move as a "cantilever beam" (He et al., 2020; Ju et al., 2011; Li 
et al., 2017; Liang et al., 2017; Wang et al., 2014; Xu and Ju, 2011; Yan et al., 2011; Yu and Yan, 2015; Yang et al., 2020; Zhang et al., 2021). Li (Li et al., 2014) constructed a strata rupture model of periodic roof weighting on a fully mechanized sub-level caving face with a large mining height and found that the support has to bear only the acting force of the inferior cantilever structure during normal recovery stages. With the decrease of bottom coal thickness, the stress concentration around roadways and coalfaces decreased rapidly and then tended to be stable ( $\mathrm{Li}$ et al., 2018; Zhu et al., 2016). The failure scopes of the coal seam and top coal on the working face present a nonlinear proportional correlation with mining thickness (Wen et al., 2019; Xie and Wang, 2010). Yan (Yan, 2009) showed that the scope of "deformation pressure strata" expands with the increase in coal seam thickness during the exploitation of super high seams, thus increasing the external loads on the support. Due to the controlling effect of critical overlying strata, the development height of water conductive fissures presents stepwise sudden changes with mining thickness rather than continuous approximate linear variations (Feng et al., 2011; Miao et al., 2011; Wang et al., 2019). Wang (Wang et al., 2018b) established the critical conditions for the loss of stability of coal walls by constructing a vertical mechanical model to analyze the influencing mechanism of mining thickness. Through a physical simulation test, Fan (Fan and Shen, 2019) found that the superior immediate roof in the overlying strata is a "simply supported beam" when the mining thickness is $30 \mathrm{~m}$, and the overburden pressure is shared by the caving gangues in the goaf, resulting in a weaker strata pressure behavior compared with that when the mining thickness is $17 \mathrm{~m}$.

Scholars have focused on mining analysis by using several mining thickness values in the same mining area or the mean coal seam thickness, but they ignored the overlying strata structural difference and mine pressure characteristics caused by continuous variations in coal seam thickness under a specific condition. This disregard leads to a serious judgment error in certain cases. To address this issue, this study analyzed the settlement characteristics of overlying strata and the evolutionary laws of critical strata during the mining of a thickening coal seam with a hard roof by combining similarity and numerical simulations on the basis of critical strata theory of strata control. The research results can provide theoretical reference for coal seam mining under similar geological conditions.

\section{PROJECT OVERVIEW}

The 4,321 fully mechanized caving face in Sangshuping Coal Mine in Hancheng City was selected as the research object. The 3 \# coal seam is undergoing exploitation. On the working face, the 3 \# coal seam is $6.08-28.41 \mathrm{~m}$ away from the 2 \# coal seam above (14.47 $\mathrm{m}$ on the average). The working face has a simple coal seam structure with a rare dirt band. The immediate roof is generally occupied by siltstone and medium sandstone with hard lithology and an average thickness of $9.83 \mathrm{~m}$. It is covered by $2 \#$ and $1 \#$ coal seams. The roof of $1 \#$ coal seam is composed of

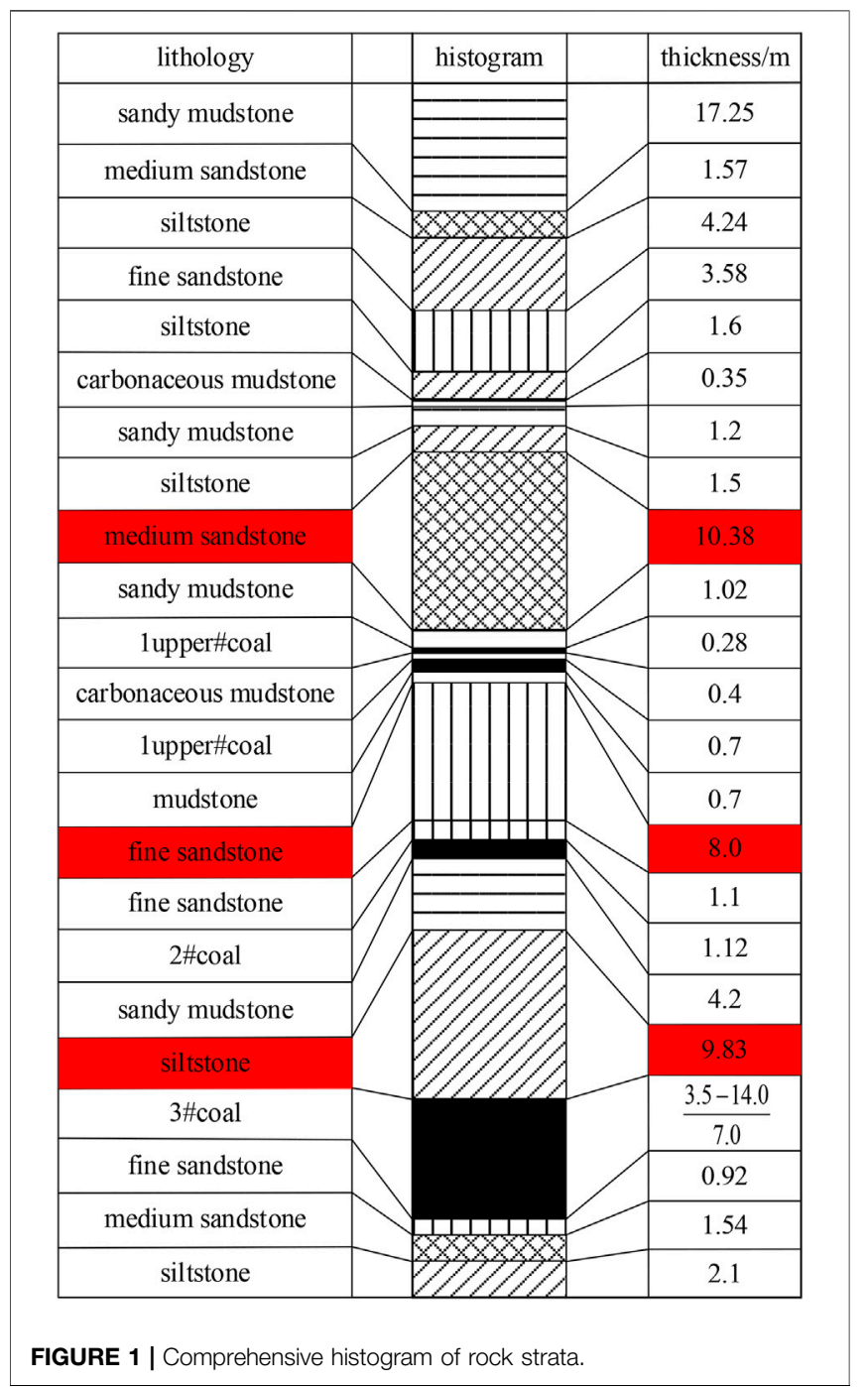

medium sandstone and fine sandstone and has an average thickness of $10.38 \mathrm{~m}$. According to evaluations of the critical overlying strata on the working face (Xu and Qian, 2000; Qian et al., 2003), the $3 \#$ coal seam has two sub-critical overlying strata made of $8.0 \mathrm{~m}$ thick fine sandstone and $10.38 \mathrm{~m}$ thick medium sandstone. A comprehensive histogram of the strata is shown in Figure 1.

In Sangshuping Coal Mine, the 3\# coal seam is soft and clamped between the upper and lower hard and thick sandstones, thus forming a composite structure of "hard-soft-hard strata." Functioning as two pieces of "washboards," the hard sandstone strata exert a strong squeezing effect on the coal seam under the action of tectonic stress. Slip surfaces are formed in the hard-soft interfaces due to differences in coal petrography, mechanical strength, and elastoplasticity, and they further develop to sliding surfaces. In the "hard-soft-hard strata" structure, the coal seam produces plastic flows that "creep" from the high-pressure zone to the lowpressure zone. Macroscopically, coal seam thickness and structure change to release stress and maintain stress balance. 


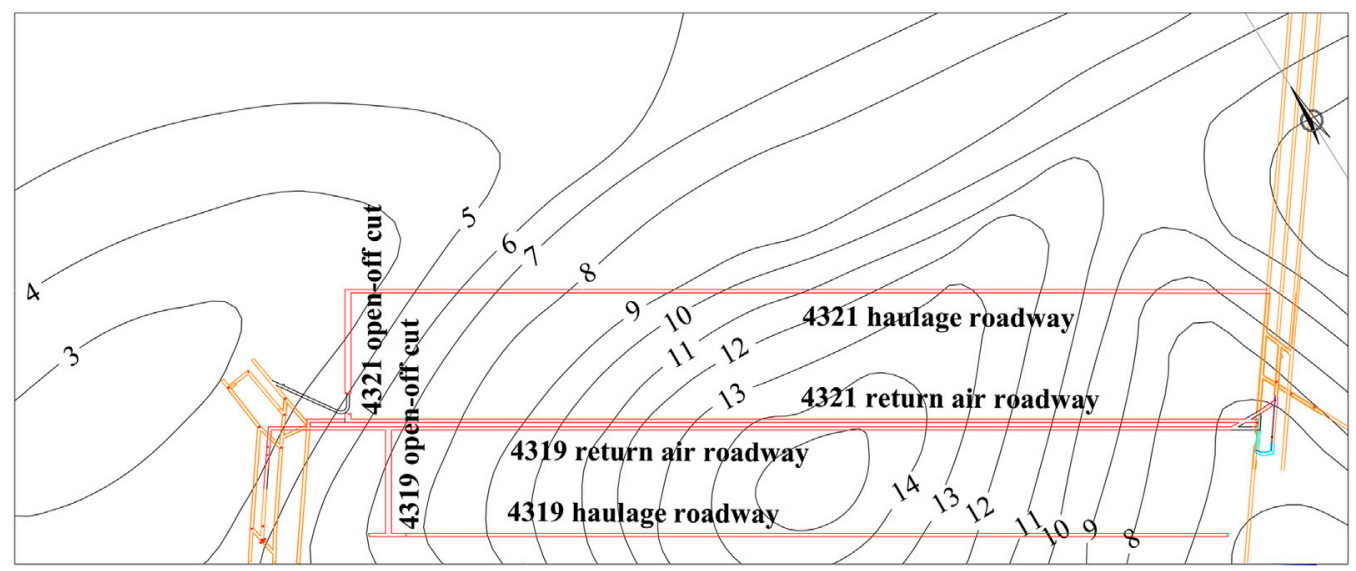

FIGURE 2 | Contour line of coal seam thickness on the 4,321 working face.

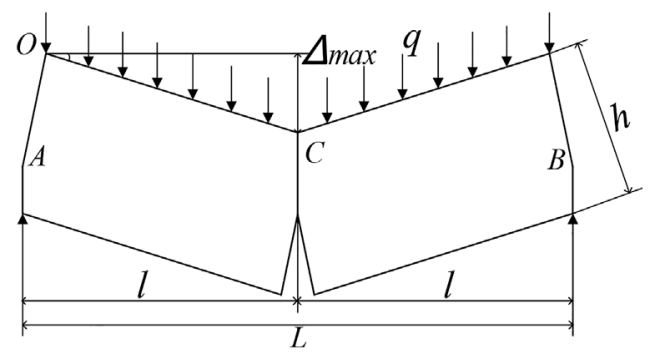

FIGURE 3 | Rotary deformation buckling model of critical blocks.

The $3 \#$ coal seam is $3.5-14 \mathrm{~m}$ thick, with an average of $7.0 \mathrm{~m}$. After advancing from the open-off cut by $500 \mathrm{~m}$, the coal seam thickness increases gradually from $3 \mathrm{~m}$ to $14 \mathrm{~m}$. The contour line of the 3 \# coal seam's thickness on the working face is shown in Figure 2.

\section{PHYSICAL SIMULATION OF THE MINING OF A THICKENING COAL SEAM WITH A HARD ROOF}

\section{Mining Thickness Conditions Formed by the "Cantilever Beam" Structure in the Critical Strata}

During the mining of a thickening coal seam with a hard roof, the structural morphology and motion characteristics of the hard immediate roof and sub-critical strata change with coal seam thickness. When the sub-critical strata are at a low level, the available gyrating mass of blocks in the sub-critical strata is higher than the ultimate value, and the masonry beam structure loses stability, thus developing into a cantilever or simply supported beam. In this section, the effects of coal seam thickness on the structure of the sub-critical strata are analyzed by combining the judgment results of the critical strata.

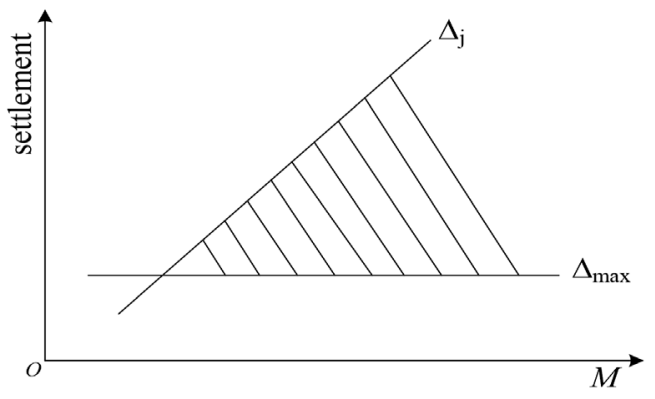

FIGURE 4 | Discrimination diagram of the structural morphology of the critical strata.

The rotary deformation buckling model of critical blocks is shown in Figure 3. $\Delta_{\max }$ is the ultimate rotary mass that is necessary for rupture blocks in the critical strata to form a stable "masonry beam" structure by hinge joints. $\Delta_{\max }$ varies in strata that have different thicknesses, strengths, and levels. It is an eigenvalue and attribute value of roof strata under a specific mining condition.

$$
\Delta_{\max }=h-\sqrt{\frac{2 q l^{2}}{\sigma_{c}}}
$$

where $h$ is the thickness of the masonry block, $q$ is the uniformly distributed load of the rock beam, $l$ is the length of the masonry block, and $\sigma_{\mathrm{c}}$ is the extrusion strength of the block at the corner.

The spatial displacement between the immediate roof after collapse and the critical strata is $\Delta_{\mathrm{j}}$.

$$
\Delta_{\mathrm{j}}=M+\left(1-K_{\mathrm{P}}\right) \sum h_{\mathrm{i}}
$$

where $M$ is the mining thickness of the coal seam $(\mathrm{m}), K_{\mathrm{P}}$ is the caving crack-expansion coefficient of the immediate roof, and $\sum h_{\mathrm{i}}$ is the sum thickness of rock strata below the critical strata $(\mathrm{m})$. 


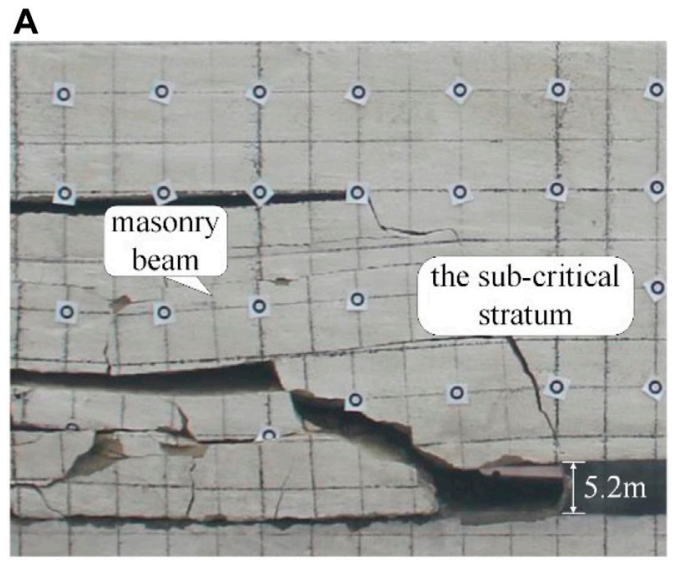

Mining thickness of $5.2 \mathrm{~m}$
B

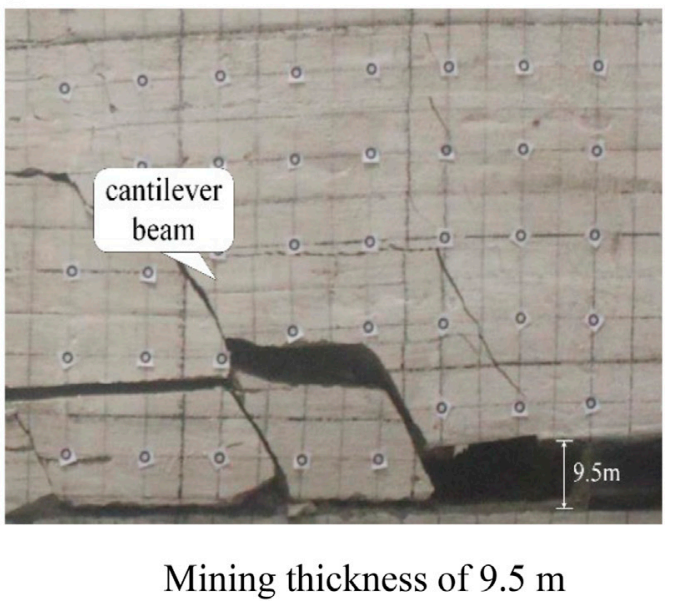

FIGURE 5 | Morphology test results of critical overlying strata during thickening coal seam mining under different mining thicknesses. (A) Mining thickness of 5.2 m; (B) Mining thickness of $9.5 \mathrm{~m}$.

The mining thickness condition for forming the "cantilever beam" structure of the low-level critical strata is

$$
M+\left(1-K_{\mathrm{P}}\right) \sum h_{\mathrm{i}}>h-\sqrt{\frac{2 q l^{2}}{\sigma_{\mathrm{c}}}}
$$

$\Delta_{\mathrm{j}}$ is a value that changes with the mining thickness of the coal seam $(M)$ and the thickness of the immediate roof $\left(\sum h_{\mathrm{i}}\right)$. It increases with the increase in $M$, thereby increasing the possibility of $\Delta_{j}>\Delta_{\max }$ significantly. As a result, the longitudinal and transverse scopes of movement of the surrounding rocks on the working face are increased.

Figure 4 indicates that with the increase in $M, \Delta_{j}>\Delta_{\max }$ is proven after entering the shadow when the "masonry beam" structure of the sub-critical strata loses its stability and becomes part of the immediate roof. It is presented as a "cantilever beam" structure.

A physical simulation test was designed to compare the structural differences of the critical overlying strata during thickening coal seam mining under the same overlying conditions and to verify the above-mentioned discriminant formula. The results are shown in Figure 5. When the mining thickness was $5.2 \mathrm{~m}$, sub-critical stratum 1 formed a "masonry beam" structure. When the mining thickness was $9.5 \mathrm{~m}$, it formed a "cantilever beam" structure, and the "masonry beam" structure shifted toward the high-level strata.

\section{Displacement and Settlement Laws of Overlying Strata in the Stope}

A laboratory $2 \mathrm{D}$ physical simulation test was performed to discuss the settlement deformation laws of the overlying strata and the evolutionary features of the structure during thickening coal seam mining. The process wherein the thickening coal seam mining advanced from $3 \mathrm{~m}$ to $10 \mathrm{~m}$ was simulated. According to the actual situation of the project site, excavate $5 \mathrm{~m}$ every $4 \mathrm{~h}$, maintain the simulated mining height of $2.3 \mathrm{~m}$, and the caving height increases with the increase of coal thickness. In the physical simulation test, the geometric similarity ratio, volume-weight similarity ratio, time similarity ratio, and stress similarity ratio were $1: 100,1: 1.6,1: 10$, and $1: 160$, respectively. The Poisson's ratio was equal to that of the prototype. The thickness values of different strata were designed as those in Figure 1. In the test, the aggregate was fine sand, and the cement used was made of lime and gypsum. The ratio is shown in Table $\mathbf{1}$.

The initial state of physical model is shown in Figure 6A and the test model design is shown in Figure 6B. Vertical displacement monitoring lines I, II, III, IV, and V were designed in the test, and they corresponded to hard immediate roof, sub-critical stratum 1 and its subsequent stratum, and subcritical stratum 2 and its subsequent stratum, respectively.

The siltstone immediate roof corresponding to Line I developed the primary rupture when the working face advanced by $90 \mathrm{~m}$. At this moment, the maximum settlement of the rock stratum was $5.037 \mathrm{~m}$. As the working face advanced, the rock stratum entered the periodic rupture stage, and the primary periodical rupture distance was $10 \mathrm{~m}$. The relevant settlement curve was a wave slope as the coal seam mining advanced forward. According to the analysis, the settlement curve was determined by the thick and hard characteristics of the immediate roof. Moreover, the settlement curve declined in a stepwise manner as the coal seam mining advanced gradually.

With the advancing of the working face, the settlement volumes of Lines II and III close to the working face became significantly higher than those at other positions in the goaf. Influenced by the hard roof, the settlement curve close to the working face had a large slope. With the increase in mining thickness of the coal seam, the settlement curve after the periodic rupture of rock strata presented a stepwise wave slope.

Lines IV and V presented an approximately symmetric "Vshaped" distribution pattern after the primary rupture of rock strata. The "V-shaped" distribution pattern after periodic 
TABLE 1 | Proportion and dosage of similar materials in the test model.

\begin{tabular}{|c|c|c|c|c|c|c|c|}
\hline \multirow[t]{2}{*}{ Seque-nce } & \multirow[t]{2}{*}{ Lithology } & \multirow[t]{2}{*}{ Thickness/m } & \multirow[t]{2}{*}{ Total weight/kg } & \multirow{2}{*}{ 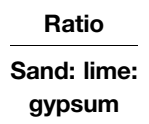 } & \multicolumn{3}{|c|}{ Weight/kg } \\
\hline & & & & & Sand & Lime & Gypsum \\
\hline 1 & siltstone & 20 & 270 & $7: 0.8: 0.2$ & 236.25 & 27 & 6.75 \\
\hline 2 & medium sandstone & 1.54 & 20.79 & $7: 0.7: 0.3$ & 18.191 & 1.819 & 0.780 \\
\hline 3 & fine sandstone & 0.92 & 12.42 & $7: 0.6: 0.4$ & 10.868 & 0.932 & 0.621 \\
\hline 4 & 3\#coal and siltstone & $17.6-24.6$ & 332.1 & $7: 0.8: 0.2$ & 290.588 & 33.21 & 8.303 \\
\hline 5 & sandy mudstone & $2.5-9.5$ & 37.8 & $8: 0.7: 0.3$ & 33.6 & 2.94 & 1.26 \\
\hline 6 & 2\#coal & 1.12 & 15.12 & 9:0.8:0.2 & 13.608 & 1.210 & 0.302 \\
\hline 7 & fine sandstone & 9.1 & 122.85 & $7: 0.6: 0.4$ & 107.494 & 9.214 & 6.143 \\
\hline 8 & 1upper\#coal & 2.08 & 28.08 & 9:0.8:0.2 & 25.272 & 2.246 & 0.562 \\
\hline 9 & sandy mudstone & 1.02 & 13.77 & $8: 0.7: 0.3$ & 12.24 & 1.071 & 0.459 \\
\hline 10 & medium sandstone & 10.38 & 140.13 & $7: 0.7: 0.3$ & 122.614 & 12.261 & 5.255 \\
\hline 11 & siltstone & 1.5 & 20.25 & $7: 0.8: 0.2$ & 17.719 & 2.025 & 0.506 \\
\hline 12 & sandy mudstone & 1.55 & 20.925 & 8:0.7:0.3 & 18.6 & 1.628 & 0.698 \\
\hline 13 & siltstone & 1.6 & 21.6 & $7: 0.8: 0.2$ & 18.9 & 2.16 & 0.54 \\
\hline 14 & fine sandstone & 3.58 & 48.33 & $7: 0.6: 0.4$ & 42.289 & 3.625 & 2.417 \\
\hline 15 & siltstone & 4.24 & 57.24 & $7: 0.8: 0.2$ & 50.085 & 5.724 & 1.431 \\
\hline 16 & medium sandstone & 1.57 & 21.195 & $7: 0.7: 0.3$ & 18.546 & 1.855 & 0.795 \\
\hline 17 & sandy mudstone & 40 & 540 & 8:0.7:0.3 & 480 & 42 & 18 \\
\hline
\end{tabular}

A

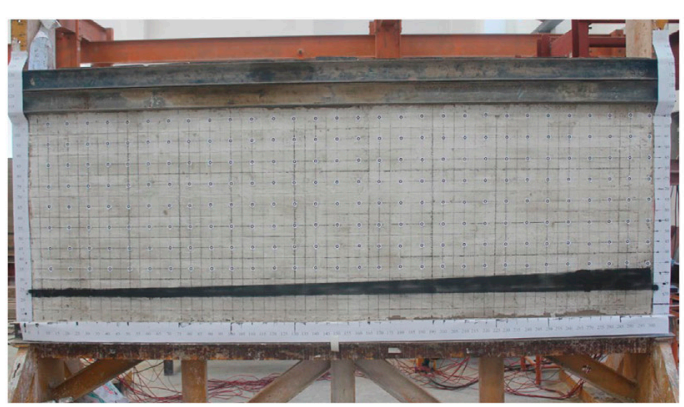

The initial state of physical model

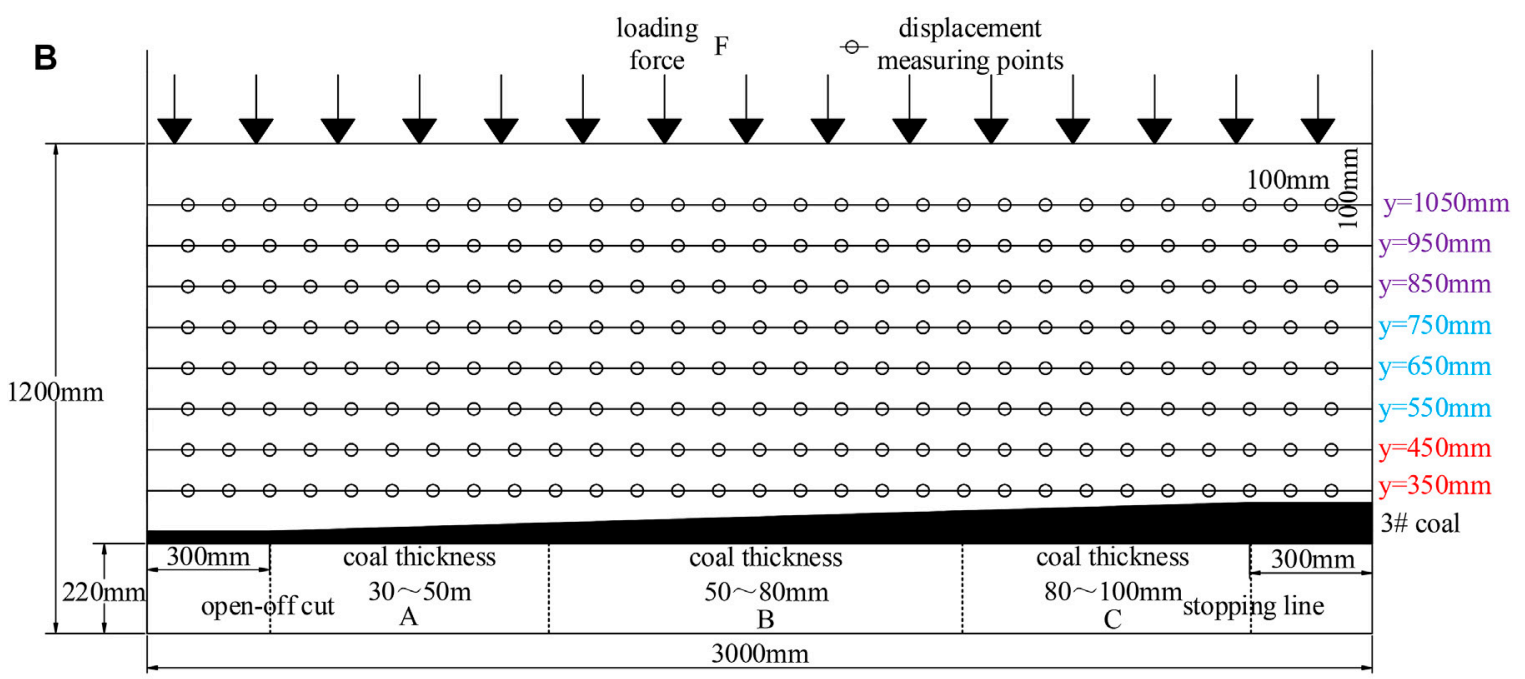

Test model design

FIGURE 6 | Model of physical simulation test. (A) The initial state of physical model; (B) Test model design. 

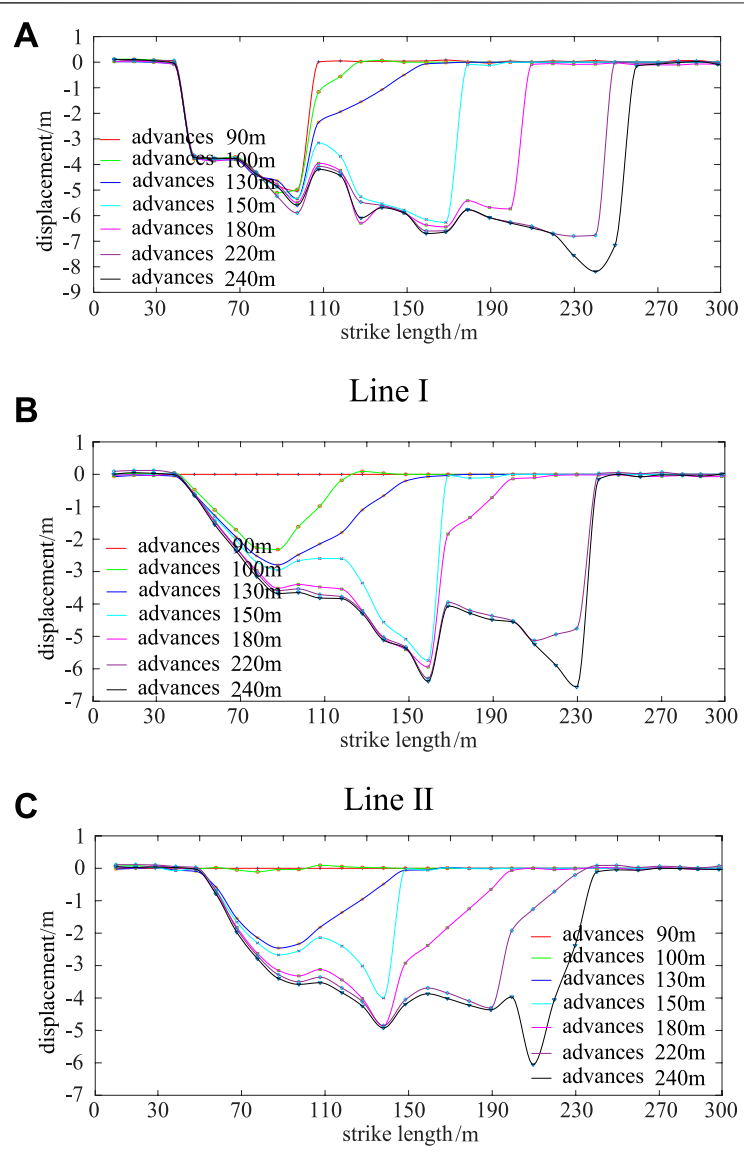

D
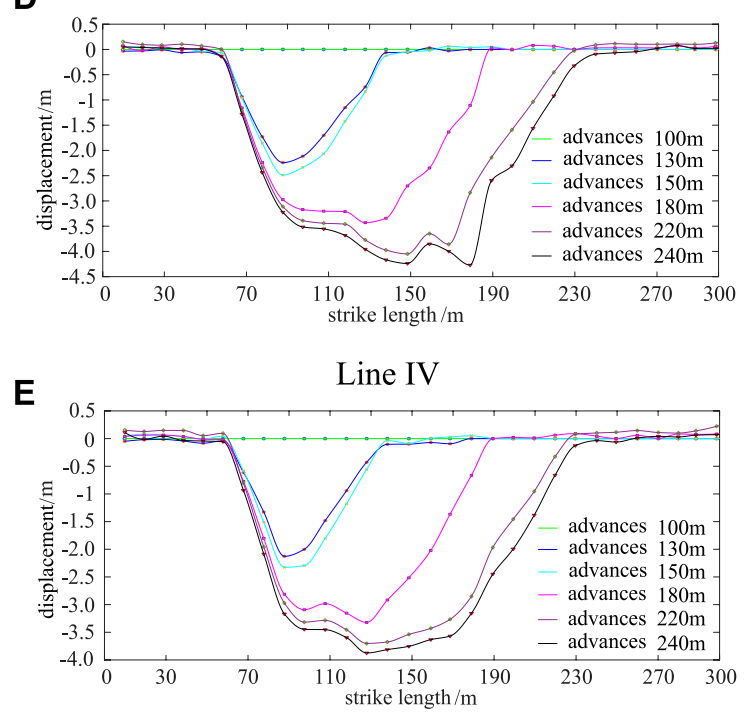

Line V

FIGURE 7 | Variations in the settlement curves of overlying strata in the recovery process. (A) Line I; (B) Line II; (C) Line III; (D) Line IV; (E) Line V.

weighting was gradually changed into a parabola pattern. As the working face advanced continuously, the parabola pattern of the settlement curve expanded continuously. The displacement at the maximum settlement point increased continuously, but the slope at the coal wall declined gradually.

The maximum settlement volume of Line I was 1.24 times that of Line II, 1.35 times that of Line III, 1.91 times that of Line IV, and 2.1 times that of Line $\mathrm{V}$. The maximum settlement volumes of the five monitoring lines indicate that the sub-critical stratum 1 of Line II and the sub-critical stratum 2 of Line IV could control the settlement deformation of overlying strata locally.

The maximum settlement volumes of the five lines were at 240 , $230,210,179$, and $128 \mathrm{~m}$ of the strike positions of the coal seam. These values indicate that the maximum settlement volumes approached the working face from the upper strata to the bottom overlying strata. This result differs significantly from the simulation results on uniformthickness coal seam mining, that is, the maximum settlement volumes of overlying strata are all located in the center of the goaf.

\section{Structural Evolution of Critical Overlying Strata in the Stope}

In accordance with the failure deformation laws of overlying strata in the physical simulation test, a structural evolution model of critical overlying strata during the mining of the thickening coal seam with a hard roof was constructed (Figure 7, Figure 8). In the early mining stage, a cantilever structure was formed due to the collapse of the hard and thick immediate roof. Sub-critical stratum 1 reached the maximum suspension step pitch and ruptured to form a threehinged arc "masonry beam" balance structure (Figure 8A). As the working face advanced, the strata structure of the cantilever beam below the masonry beam developed periodic sliding buckling at the coal wall. With the subsequent increase in coal seam thickness, the bed-separated fissures between the cantilever beam structure and the masonry beam structure expanded further. The available rotary deformation volume of the masonry beam blocks increased, placing the masonry beam in the critical buckling state (Figure 8B). With the increase in mining thickness, the available rotary volume of the masonry beam blocks formed by sub-critical stratum 1 exceeded the ultimate value, resulting in rotary deformation buckling of the low-level masonry beam structure. The masonry beam structure formed a composite cantilever beam with the immediate roof beneath and the upper supporting stratum (Figure 8C). With the continuous advancement of the working face, the composite cantilever beam structure developed periodic ruptures and slid at the coal wall. Meanwhile, the masonry beam structure was formed at a high level, and the "small structures" at the rear positions of the coal wall were changed. New forms of composite strata structure and motion state were developed (Figure 8D).

\section{NUMERICAL SIMULATION \\ Construction of a Numerical Simulation Model}

The coal seams, roof, and floor in the model were designed based on the deposition characteristics of coal seams on the 4,321 working face and mining technological conditions. The $3 \mathrm{D}$ numerical simulation model is shown in Figure 9. In this model, the lengths in the $x$ and $y$ directions were 900 and 570 


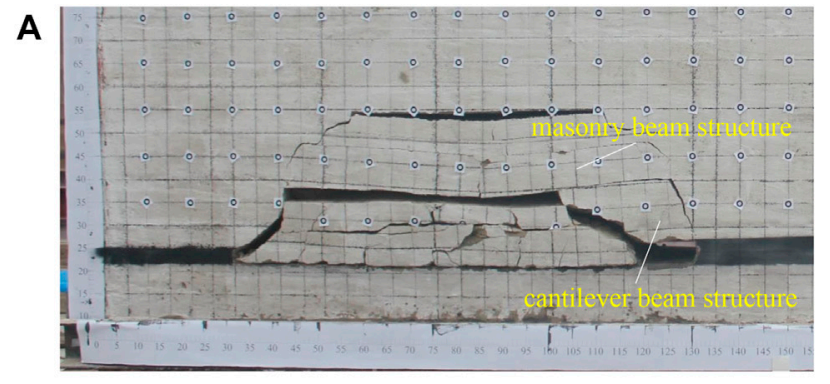

Sub-critical stratum 1 presents a "masonry beam"

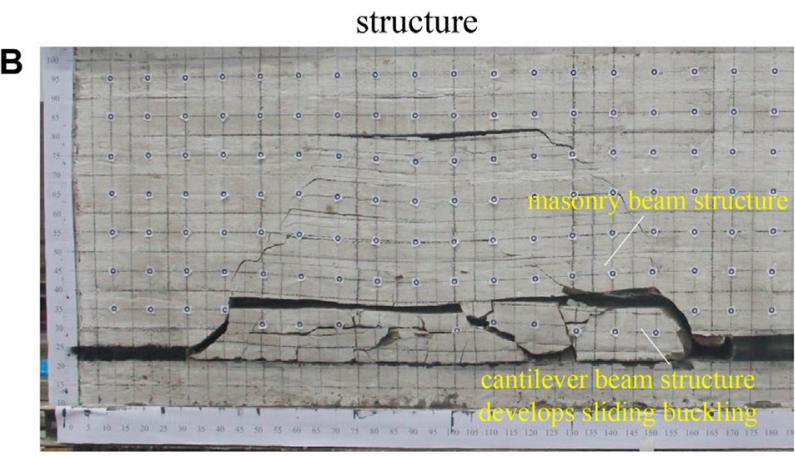

"Cantilever beam" structure of the hard immediate roof develops sliding buckling

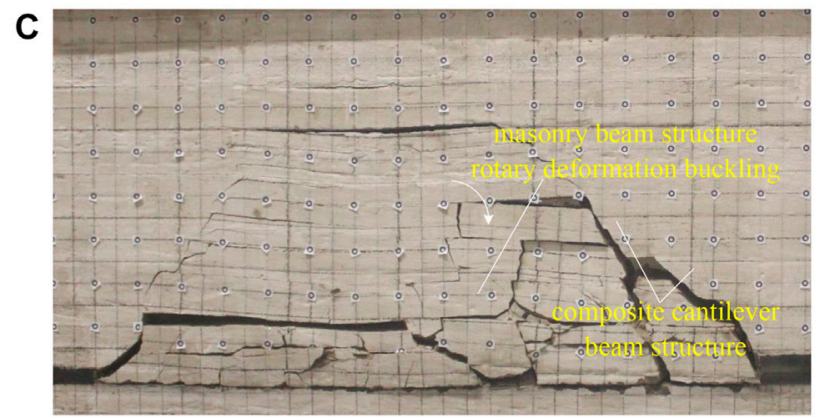

"Masonry beam" structure of sub-critical stratum 1 shows rotary deformation buckling

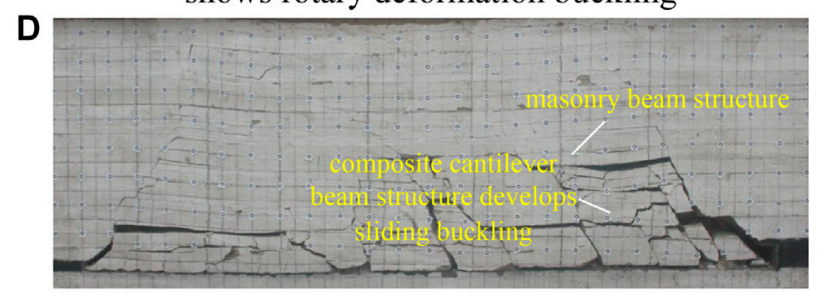

"Composite cantilever beam" structure develops sliding buckling

FIGURE 8 | Structural evolution model of the critical strata. (A) Subcritical stratum 1 presents a "masonry beam"; (B) "Cantilever beam" structure of the hard immediate roof develops sliding buckling; (C) "Masonry beam" structure of sub-critical stratum 1 shows rotary deformation buckling; (D) "Composite cantilever beam" structure develops sliding buckling. $\mathrm{m}$, respectively, and the height in the $z$ direction was $200 \mathrm{~m}$. Normal constraints were applied at the sides and bottom to restrict horizontal and vertical movements. The stress boundary was used at the top. However, equivalent compensation loads of 4.7 MPa on the strata were not simulated. The corresponding physical and mechanical parameters for the numerical simulation are shown in Table 2.

The advancing length of the thickening coal seam was $300 \mathrm{~m}$, and the width of the working face was $170 \mathrm{~m}$. The $200 \mathrm{~m}$ boundary pillars were retained at two ends of the advancing direction ( $x$ direction) and surface length direction ( $y$ direction) to analyze evolution laws of the plastic zone of the surrounding rocks caused by the mining of thickening coal seams with a hard roof and to eliminate the boundary effects. The coal seam was excavated at $200 \mathrm{~m}$ away from the boundaries of the model, and it entered into the thickening coal seam zone $(x=400-700 \mathrm{~m})$ after advancing by $200 \mathrm{~m}(x=200-400 \mathrm{~m})$.

\section{Analysis of Numerical Simulation Results}

The internal stress in overlying strata is redistributed after the mining of thickening coal seams. Rock strata rupture when the stress over the rock strata is greater than the rock strength, which further influences the transmission, release, and redistribution of stresses and lithological changes. The numerical simulation results during thickening coal seam mining are shown in Figure 10. Influenced by the supports of the coal pillars, areas of strong tensile stress concentration occurred in the open-off cut in the goaf and the upper inclined rock strata at the coal walls. The plastic failure zone developed the most, and a plastic failure distribution pattern of "high at two ends and low in the middle" was formed preliminarily. Influenced by the increasing mining thickness of the thickening coal seam, the tensile failure zone of the roof expanded continuously toward the high places.

At the end of recovery, the plastic failure zone of the overlying strata of the thickening coal seam had obvious characteristics of longitudinal and transverse partitions after achieving the steady-movement state. Longitudinally, the low-level strata area of the thickening coal seam developed tensile failure because of the two-way tensile stresses, showed the development of fractures and separation layer, and collapsed. On this basis, this area was determined to be the caving zone. The stresses over the roof strata at middle-level and high-level positions exceeded the yield or shear strength. Shear plastic failure played the dominant role. Hence, the development height of the strata state in this area was defined as the upper limit of the fissure zone. The stress state in these strata areas was still in the elastic deformation stage, and these areas were defined as the bending settlement belt. Transversely, the roof tensile and shear plastic failure zone in the thick coal seams was significantly larger than that in the thin coal seams. Shear failure was the major mode in the coal mass in front of the boundary pillars and above the rock strata. The plastic zones at the two sides of the stope were higher than those above the stope. The plastic zone close to the open-off cut was relatively higher than that at the coal walls of the working face. 


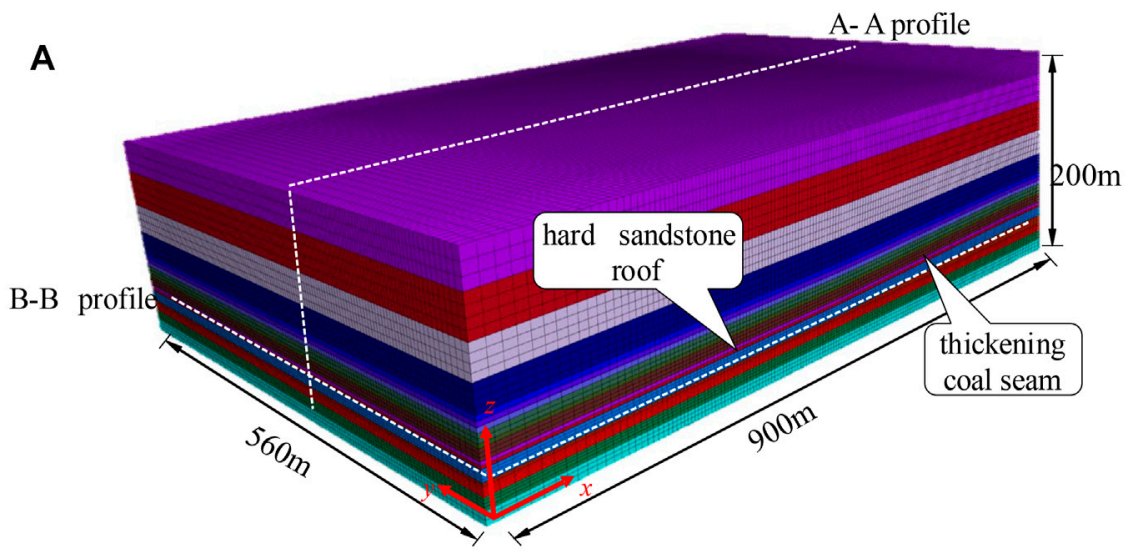

B Meshing

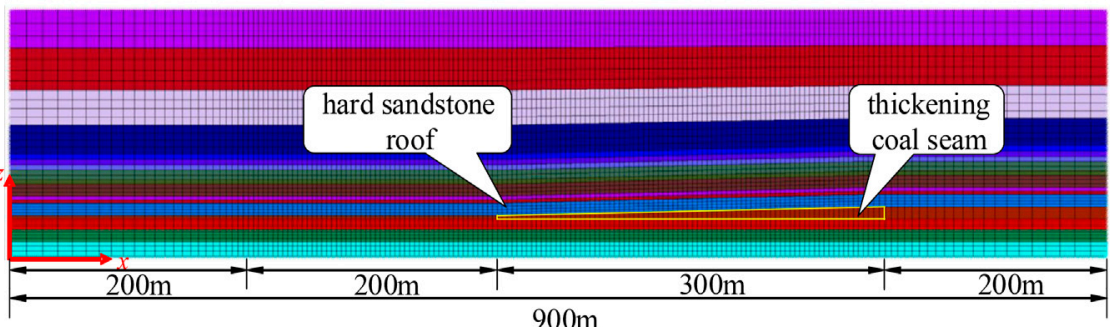

A-A profile map along the coal tendency

FIGURE 9 | Numerical calculation mesh model. (A) Meshing; (B) A-A profile map along the coal tendency.

TABLE 2 | Physical and mechanical parameters.

\begin{tabular}{|c|c|c|c|c|c|c|}
\hline Lithology & Density/kg $\cdot \mathrm{m}^{-3}$ & Elastic modulus/Gpa & Poisson's ratio & Tensile strength/Mpa & Cohesion/Mpa & $\begin{array}{l}\text { Internal friction } \\
\text { angle } /^{\circ}\end{array}$ \\
\hline siltstone & 2,620 & 26.7 & 0.2 & 3.3 & 6.34 & 37.33 \\
\hline medium sandstone & 2,690 & 35.5 & 0.18 & 5.5 & 7.47 & 38.48 \\
\hline fine sandstone & 2,640 & 35.9 & 0.19 & 8.5 & 7.68 & 38.7 \\
\hline 3\#coal & 1,400 & 5.31 & 0.33 & 1.32 & 1.25 & 32 \\
\hline sandy mudstone & 2,650 & 19.47 & 0.22 & 2.5 & 5.75 & 36.43 \\
\hline 2\#coal & 1,400 & 5.31 & 0.33 & 1.32 & 1.25 & 32 \\
\hline 1upper\#coal & 1,400 & 5.31 & 0.33 & 1.32 & 1.25 & 32 \\
\hline
\end{tabular}

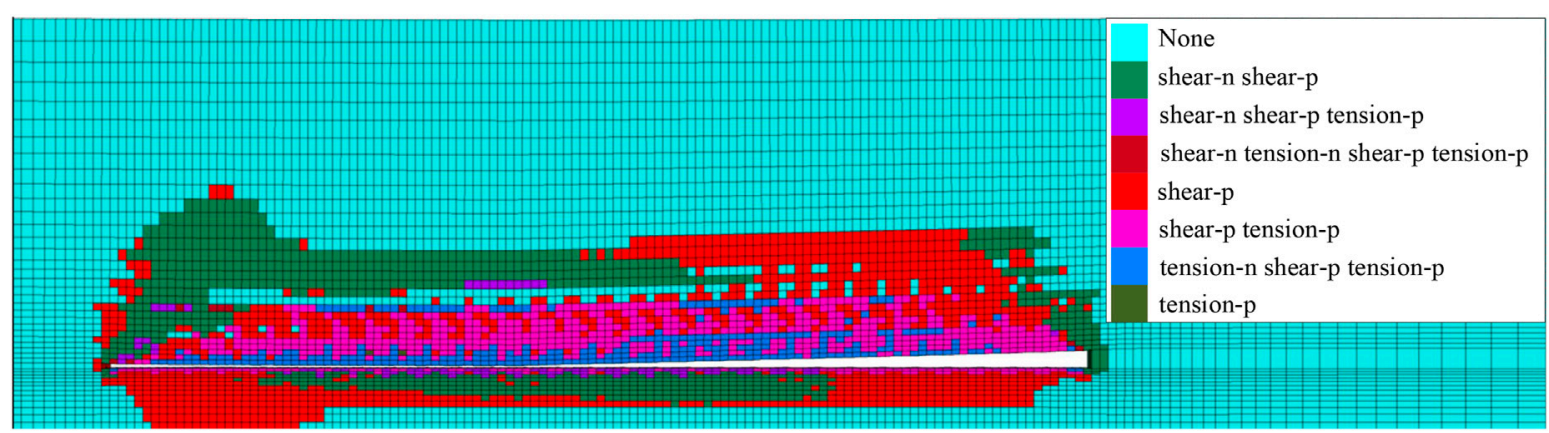

FIGURE 10 | Evolutionary laws of plastic zones during thickening coal seam mining. 


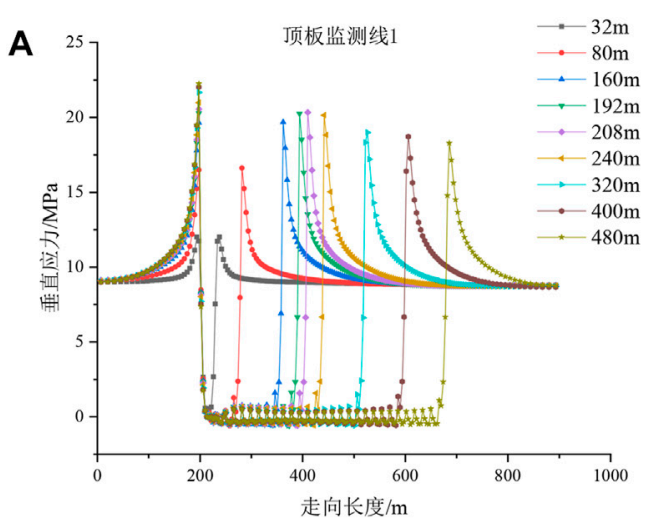

Roof monitoring line 1

( $5 \mathrm{~m}$ above the coal seam)

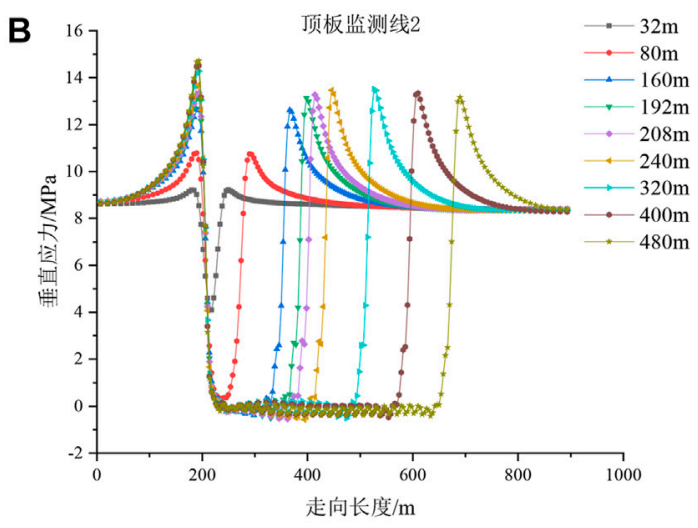

Roof monitoring line 2

( $19 \mathrm{~m}$ above the coal seam)

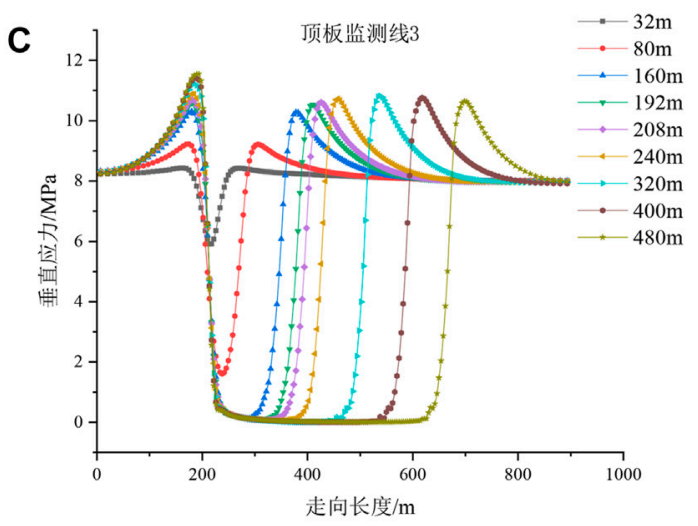

Roof monitoring line 3

(33m above the coal seam)

FIGURE 11 | Variation of vertical stress curve during working face advancement. (A) Roof monitoring line 1 (5m above the coal seam); (B) Roof monitoring line 2 (19 $\mathrm{m}$ above the coal seam); (C) Roof monitoring line 3 (33 m above the coal seam).
Figure 11 is the vertical stress variation curve of the roof in different layers with coal seam excavation, in which roof 1 , roof 2 , and roof 3 are 5, 19, and $33 \mathrm{~m}$ away from the coal seam respectively, and the layers correspond to thick and hard direct roof, sub key layer 1 , and sub key layer 2 respectively.

In the area with no change in coal thickness (within the excavation range of $0-200 \mathrm{~m}$ ), during the simulated coal seam excavation, the peak value of advance bearing pressure of roof 1 is $20.26 \mathrm{MPa}$ and the stress concentration factor is 2.31. The peak value of advance bearing pressure of roof 2 is $13.14 \mathrm{MPa}$ and the stress concentration factor is 1.57 . The peak value of advance bearing pressure of roof 3 is $10.53 \mathrm{MPa}$ and the stress concentration factor is 1.31 . In the $3-10 \mathrm{~m}$ unequal thickness coal seam area (within the excavation range of $200-500 \mathrm{~m}$ ), during the simulated coal seam excavation, the peak advance bearing pressure of roof 1 is $20.33 \mathrm{MPa}$ and the stress concentration factor is 2.32 . The peak value of advance bearing pressure of roof 2 is $13.52 \mathrm{MPa}$ and the stress concentration factor is 1.61 . The peak value of advance bearing pressure of roof 3 is $10.82 \mathrm{MPa}$ and the stress concentration factor is 1.35 . It shows that different distances from the coal seam have a significant impact on the stress distribution of the roof. The closer to the coal seam, the more significant the stress concentration effect caused by the excavation of the coal seam.

In the mining area of unequal thickness coal seam, the thickness of coal seam increases continuously. Under the action of "cushion" of top coal, the stress distribution in the front arch foot and arch of stress arch evolves, the peak value of advance bearing pressure gradually decreases, and the peak position gradually goes deep into the coal body.

\section{CONCLUSION}

Through the analysis of the roof structure of a hard roof during thickening coal seam mining, the physical simulation test and numerical simulation calculation are carried out. The structural evolution and motion characteristics of roof structure are studied, and the following conclusions are drawn:

1) The mining thickness conditions for structural changes in low-level critical strata during the mining of thickening coal seams with a hard roof were deduced and verified through a simulation test.

2) The settlement curve of low-level strata presented a stepwise wave slope. The settlement curve of the high-level strata changed from a " $\mathrm{V}$ " pattern into a parabola pattern with the full mining of the coal seam. From top to bottom, the position of the maximum settlement volume of the overlying strata approached the working face. We conclude that subcritical strata have local control over the settlement of overlying strata. 
3) With the increase in mining thickness, the available rotary volume of "masonry beam" blocks in the low-level critical strata increased continuously, and the masonry structure lost its stability gradually, entering into the caving zone. The "masonry beam" structure formed a "composite cantilever beam" structure with the hard immediate roof beneath.

4) A numerical model was established by combining practical geological conditions to simulate thickening coal seam mining. After the overlying strata achieved movement stability, the plastic failure zone presented obvious characteristics of longitudinal and transverse partitions.

\section{DATA AVAILABILITY STATEMENT}

The original contributions presented in the study are included in the article/supplementary material, and further inquiries can be directed to the corresponding author.

\section{REFERENCES}

Fan, K. s., and Shen, B. h. (2019). Research on Mining Thickness Effect of Underground Mine Pressure Behavior by Fully-Mechanized Caving Mining in Extra Thick Coal Seams. Coal Sci. Tech. 47 (3), 239-243. doi:10.13199/j.cnki. cst.2019.03.036

Feng, S. j., Sun, S. g., Lv, Y. g., and Lv, J. (2011). Research on the Height of Water Flowing Fractured Zone of Fully Mechanized Caving Mining in Extra-thick Coal Seam. Proced. Eng. 26, 466-471. doi:10.1016/j.proeng.2011.11.2193

Gao, M., Xie, J., Gao, Y., Wang, W., Li, C., Yang, B., et al. (2021). Mechanical Behavior of Coal under Different Mining Rates: A Case Study from Laboratory Experiments to Field Testing. Int. J. Mining Sci. Tech. 31, 825-841. doi:10.1016/ j.ijmst.2021.06.007

He, F. l., Li, X. b., He, W. r., Zhao, Y. Q., Xu, Z., and Li, Q. S. (2020). The Key Stratum Structure Morphology of Longwall Mechanized Top Coal Caving Mining in Extra-thick Coal Seams: a Typical Case Study. Adv. Civil Eng. 2020, 1-13. Article ID 7916729, 13 pages. doi:10.1155/2020/7916729

Huang, Q. x., Zhou, J. 1., and Cao, J. (2020). Key Stratum Structure and Support Working Resistance of Longwall Face with Large Mining Height in the Shallow Coal Seams, china. Adv. Civil Eng., 2020. Article ID 8834403, 14 pages. 1-14 doi: $10.1155 / 2020 / 8834403$

Ju, J. f., Xu, J. l., and Wang, Q. x. (2011). Cantilever Structure Moving Type of Key Strata and its Influence on Ground Pressure in Large Mining Height Workface. J. China Coal Soc. 36 (12), 2115-2120. doi:10.13225/j.cnki.jccs.2011.12.028

Kong, D., Lou, Y., Zheng, S., and Pu, S. (2020). The Characteristics of Roof Breaking and the Law of Ground Pressure Behavior in Fully Mechanized TopCoal Caving Face with Large Mining Height. Geotech Geol. Eng. 39, 285-297. doi:10.1007/s10706-020-01492-2

Li, H. m., Jiang, D. j., and Li, D. y. (2014). Analysis of Ground Pressure and Roof Movement in Fully-Mechanized Top Coal Caving with Large Mining Height in Ultra-thick Seam. J. China Coal Soc. 39 (10), 1956-1960. doi:10.13225/j.cnki. jccs.2013.1366

Li, M., Zhang, J.-x., Huang, Y.-l., and Gao, R. (2017). Measurement and Numerical Analysis of Influence of Key Stratum Breakage on Mine Pressure in Top-Coal Caving Face with Super Great Mining Height. J. Cent. South. Univ. 24 (8), 1881-1888. doi:10.1007/s11771-017-3595-5

Li, Z.-l., He, X.-q., Dou, L.-m., Song, D.-z., and Wang, G.-f. (2018). Numerical Investigation of Load Shedding and Rockburst Reduction Effects of Top-Coal Caving Mining in Thick Coal Seams. Int. J. Rock Mech. Mining Sci. 110, 266-278. doi:10.1016/j.ijrmms.2018.08.005

\section{AUTHOR CONTRIBUTIONS}

XZhang and LL designed experiments. XZhao and LL carried out the experiments. XZhang and XZhao analyzed the experimental results. XZhao and LL wrote the manuscript.

\section{FUNDING}

This work was conducted with support from the National Natural Science Funded Projects (award no. 52074007) and Anhui Province Natural Science Funded Projects (award no. 2008085ME142).

\section{ACKNOWLEDGMENTS}

We thank Hancheng Mining Group and Anhui University of Science and Technology for giving us access to the mine, data, and physical resources necessary to complete this work.

Liang, Y. p., Li, B., Yuan, Y., et al. (2017). Moving Type of Key Strata and its Influence on Ground Pressure in Fully Mechanized Mining Face with Large Mining Height. J. China Coal Soc. 42 (06), 1380-1391. doi:10.13225/j.cnki.jccs. 2016.1320

Miao, X., Cui, X., Wang, J. a., and Xu, J. (2011). The Height of Fractured WaterConducting Zone in Undermined Rock Strata. Eng. Geology. 120, 32-39. doi:10. 1016/j.enggeo.2011.03.009

Qian, M. g., Miao, X. x., Xu, J. 1., and Mao, X. b. (2003). "Study of Key Strata Theory in Ground Control," Xuzhou. China University of Mining and Technology Press, 16-18.

Wang, J. 1., Yuan, Y., Tu, S. h., and Li, B. (2014). Roof Structure Characteristics in Fully Mechanized Coalface with Large Mining Height and Reasonable Loading of Support. J. Mining Saf. Eng. 31 (4), 512-518. doi:10.13545/j.issn1673-3363. 2014.04.003

Wang, X., Wen, Z. j., Jiang, Y. j., and Huang, H. (2018a). Experimental Study on Mechanical and Acoustic Emission Characteristics of Rock-like Material under Non-uniformly Distributed Loads. Rock Mech. Rock Eng. 51 (03), 729-745. doi:10.1007/s00603-017-1363-3

Wang, H. w., Wu, Y. p., Xie, P. s., Luo, S. h., Liu, K. z., and Liu, M. f. (2018b). Coal Rib Stability Effect of Mining-Thickness with Large Mining Height of Working Face in Steeply Inclined Seams. J. Mining Saf. Eng. 35 (1), 64-70. doi:10.13545/j. cnki.jmse.2018.01.009

Wang, X. z., Xu, J. l., Han, H. k., Ju, J. f., and Xing, Y. t. (2019). Stepped Development Characteristic of Water Flowing Fracture Height with Variation of Mining Thickness. J. China Coal Soc. 44 (12), 3740-3749.

Wen, J., Li, H., Jiang, F., Yu, Z., Ma, H., and Yang, X. (2019). Rock Burst Risk Evaluation Based on Equivalent Surrounding Rock Strength. Int. J. Mining Sci. Tech. 29 (4), 571-576. doi:10.1016/j.ijmst.2019.06.005

Xu, J. I, and Qian, M. g. (2000). Method to Distinguish Key Strata in Overburden. J. China Univ. Mining Tech. 29 (05), 463-467.

Xie, G. x., and Wang, L. (2010). Thickness Effects of Fracture Characteristics of Coal Seam and Surrounding Rocks in Fully Mechanized Top-Coal Caving Face. J. China Coal Soc. 35 (02), 177-181. doi:10.13225/j.cnki.jccs.2010.02.010

$\mathrm{Xu}$, J. 1., and Ju, J. f. (2011). Structural Morphology of Key Strata and its Influence on Strata Behavior in Fully-Mechanized Face with Super Great Mining Height. ”. Chin. J. Rock Mech. Eng. 30 (08), 1547-1556.

Yan, S. h. (2009). Theory Study on the Load on Support of Long wall with Top Coal Caving with Great Mining Height in Extra Thick Coal Seam. J. China Coal Soc. 34 (05), 590-593.

Yan, S. h., Yin, X. w., Xu, H. j., Li, B., Yan, S. H., YIn, X. W., et al. (2011). Roof Structure of Short Cantilever-Articulated Rock Beam and Calculation of 
Support Resistance in Full-Mechanized Face with Large Mining Height. J. China Coal Soc. 36 (11), 1816-1820. doi:10.13225/j.cnki.jccs.2011.11.022

Yang, D., Zhang, Y., Chen, Z., and Chen, Z. h. (2020). Analysis on Catastrophe Theory during First Weighting Sliding Instability and Support Crushing of Main Roof with Large Mining Height in Shallow Coal Seam. Appl. Sci. 10 (16), 5408. doi:10.3390/app10165408

Yu, L., and Yan, S. h. (2015). Study on Roof Movement Form and Mine Strata Pressure Law of Fully-Mechanized Top Coal Caving Mining in Ultra Thick Seam. Coal Sci. Tech. 43 (08), 40-44+59. doi:10.13225/j.cnki.jccs. 2011.11 .022

Zhang, B. s., Yang, Z. p., Ji, C. X., Guo, Z., and Li, H. Y. (2021). Research on the Influence of the Key Stratum Position on the Support Working Resistance during Large Mining Height Top-Coal Caving Mining. Adv. Civil Eng. 2021, 1-9. Article ID 6690280, 9 pages. doi:10.1155/2021/6690280

Zhang, D. 1., and Wang, Y. h. (1998). Analysis of Strata Structure in Fully Mechanized Sub Level Caving Faces. Xuzhou: J. China Univ. Mining Tech. 04, 340-343.

Zhu, G. a., Dou, L. m., Li, Z. 1., Cai, W., Kong, Y., and Li, J. (2016). Mininginduced Stress Changes and Rock Burst Control in a Variable-Thickness
Coal Seam. Arabian J. Geosciences 9 (5), 365. doi:10.1007/s12517-0162356-3

Conflict of Interest: The authors declare that the research was conducted in the absence of any commercial or financial relationships that could be construed as a potential conflict of interest.

Publisher's Note: All claims expressed in this article are solely those of the authors and do not necessarily represent those of their affiliated organizations, or those of the publisher, the editors, and the reviewers. Any product that may be evaluated in this article, or claim that may be made by its manufacturer, is not guaranteed or endorsed by the publisher.

Copyright (c) 2022 Zhang, Zhao and Luo. This is an open-access article distributed under the terms of the Creative Commons Attribution License (CC BY). The use, distribution or reproduction in other forums is permitted, provided the original author(s) and the copyright owner(s) are credited and that the original publication in this journal is cited, in accordance with accepted academic practice. No use, distribution or reproduction is permitted which does not comply with these terms. 